\title{
Rotational thromboelastometry and aortic surgery
}

\author{
Ming-Sing Si, MD
}

From the Section of Pediatric Cardiovascular Surgery, Department of Cardiac Surgery, University of Michigan, Ann Arbor, Mich.

Disclosures: Author has nothing to disclose with regard to commercial support.

Received for publication July 18, 2018; accepted for publication July 21, 2018; available ahead of print Aug 31, 2018.

Address for reprints: Ming-Sing Si, MD, 11-735 C.S. Mott Children's Hospital, SPC 4204, 1540 E Hospital Dr, Ann Arbor, MI, 48109-4204 (E-mail: mingsing@umich.edu).

J Thorac Cardiovasc Surg 2019;157:1058

$0022-5223 / \$ 36.00$

Copyright (c) 2018 by The American Association for Thoracic Surgery

https://doi.org/10.1016/j.jtcvs.2018.07.058

One of the banes of a cardiac surgeon is the bleeding that can occur after a case with cardiopulmonary bypass. This bleeding tends to be worse with aortic surgery, because there are longer suture lines containing high-pressure blood flow and because coagulopathy tends to be more prevalent for a variety of reasons. Consequently, blood use may be more significant after aortic surgery.

Point-of-care measurement of clot viscoelasticity by rotational thromboelastometry (ROTEM) is a quick and semiquantitative method to assess the coagulation status. ${ }^{1}$ ROTEM has been shown to decrease blood product use in several clinical trials and observational studies of adult and pediatric cardiac surgical patients. ${ }^{2-4}$

In this issue of the Journal, St-Onge and colleagues ${ }^{5}$ present another study of ROTEM application in 188 patients undergoing aortic surgery at their center. They distinguish their study from the clinical trials mentioned previously as a "real-world" application of ROTEM. St-Onge and colleagues ${ }^{5}$ used a propensity score-matched population of 197 aortic surgical patients operated at the same institution before the adoption of ROTEM and compared the postoperative use of blood products between the groups. Their analyses found a trend toward a decreased rate of red blood cell transfusion and a significantly decreased number of units of RBCs and plasma transfused. Sensitivity analysis tempered the difference; however, the number of RBC units transfused was still less in the ROTEM group. St-Onge and colleagues ${ }^{5}$ concluded that ROTEM might be useful in reducing the amount of red blood cell transfusion needed after complex aortic procedures in the real-world setting.

Results and conclusions obtained from clinical trials are usually designed to answer a specific question and may therefore be difficult to apply to the general population of patients. Real-world evidence obtained from observational and retrospective studies, such as the one performed by St-Onge and colleagues, ${ }^{6}$ is information and data that are obtained from the clinical setting outside the research environment. ${ }^{6}$ Real-world evidence can thus be very

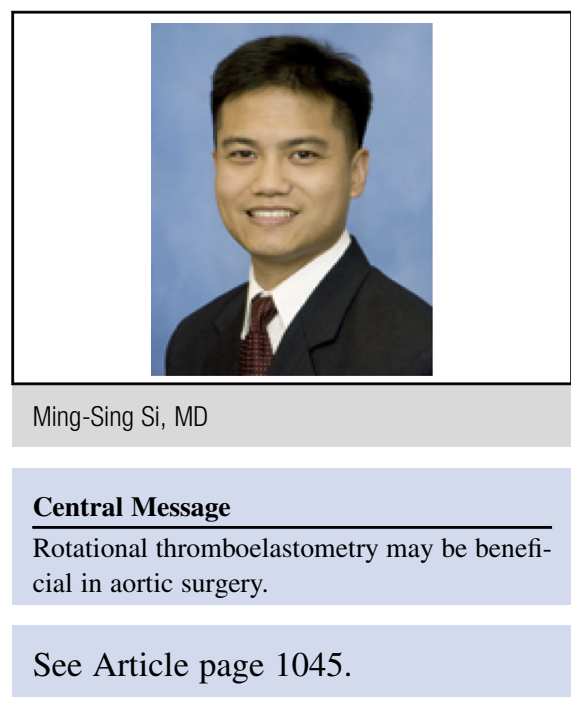

informative when analyzed appropriately. Specifically, confounding variables must be taken into account when comparing 2 populations of patients before being able to make a causal inference that a specific intervention (eg, the use of ROTEM), resulted in a measurable effect (eg, decreased red blood cell transfusion). St-Onge and colleagues ${ }^{5}$ used the usual statistical methods of propensity score matching followed by sensitivity analysis to accomplish this. In light of this real-world evidence, serious consideration should be given to the universal adoption of ROTEM-driven protocols for blood product use after aortic and other types of cardiac surgery.

\section{References}

1. Whiting D, DiNardo JA. TEG and ROTEM: technology and clinical applications. Am J Hematol. 2014;89:228-32.

2. Nakayama Y, Nakajima Y, Tanaka KA, Sessler DI, Maeda S, Iida J, et al. Thromboelastometry-guided intraoperative haemostatic management reduces bleeding and red cell transfusion after paediatric cardiac surgery. Br J Anaesth. 2015; 114:91-102.

3. Pearse BL, Smith I, Faulke D, Wall D, Fraser J, Ryan EG, et al. Protocol guided bleeding management improves cardiac surgery patient outcomes. Vox Sang. 2015;109:267-79.

4. Trevisan D, Zavatti L, Gabbieri D, Pedulli M, Giordano G, Meli M. Point-of-carebased protocol with first-line therapy with coagulation factor concentrates is associated with decrease allogenic blood transfusion and costs in cardiovascular surgery: an Italian single-center experience. Minerva Anestesiol. 2016;82:1077-88.

5. St Onge S, Lemoine E, Bouhout I, Rochon A, El-Hamamsy I, Lamarche Y, et al. Evaluation of the real-world impact of rotational thromboelastometry-guided transfusion protocol in patients undergoing proximal aortic surgery. J Thorac Cardiovasc Surg. 2019;157:1045-54.

6. Sherman RE, Anderson SA, Dal Pan GJ, Gray GW, Gross T, Hunter NL, et al. Real-world evidence-what is it and what can it tell us? N Engl J Med. 2016; 375:2293-7. 